\title{
Rancang bangun inverter satu fasa SPWM dengan output tegangan dan frekuensi variabel
}

\author{
Moch. Kusuma Wardana ${ }^{1}$, Irham Fadlika², Ahmad Fahmi ${ }^{3}$ \\ 1. Universitas Negeri Malang, Indonesia | mochkusumawardana@um.ac.id \\ 2. Universitas Negeri Malang, Indonesia | irham.fadlika.ft@um.ac.id \\ 3. Universitas Negeri Malang, Indonesia | ahmad.fahmi.ft@um.ac.id
}

\begin{abstract}
Abstrak
Penelitian ini bertujuan untuk merancang inverter satu fasa untuk mengatur nilai frekuensi dan tegangan AC pada keluaran inverter. Hal ini dimaksudkan untuk memperbaiki atau meningkatkan efisiensi energi listrik pada beban satu fasa. Sistem ini dapat direalisasikan dengan menggunakan mikrokontroler, sehingga lebih ekonomis dan cocok untuk kebutuhan industri dan rumah tangga. Tegangan keluaran inverter diatur dengan mengubah nilai puncak pada output konverter SEPIC pada sisi terminal input inverter, sedangkan frekuensi output inverter diatur melalui modulasi SPWM. Untuk memvalidasi metode yang diusulkan, prototipe inverter satu fasa dengan kapaistas $150 \mathrm{~W}$ dirancang dan diuji di laboratorium. Penelitian ini dapat menjadi teknologi alternatif yang tepat guna dan mampu bersaing dengan teknologi yang telah ada saat ini.
\end{abstract}

\section{Kata Kunci}

Inverter satu fasa, konverter SEPIC, SPWM, efisien.

TEKNO Vol. 28 Issue 1, p1-16 | Jurusan Teknik Elektro, Universitas Negeri Malang, Indonesia | Maret 2018

M. K. Wardana, I. Fadlika, A. Fahmi | Rancang Bangun Inverter Satu Fasa SPWM dengan Output Tegangan dan Frekuensi judul... 


\section{TEKNO Jurnal Teknologi, Elektro, dan Kejuruan}

http://journal2.um.ac.id/index.php/tekno | ISSN 1693-8739

\section{Pendahuluan}

Perkembangan teknologi yang semakin maju membuat manusia terus berinovasi menemukan hal-hal baru khususnya dalam teknologi kelistrikan. Inverter merupakan salah satu bentuk kemajuan teknologi dalam kelistrikan. Secara etimologi, inverter berasal dari bahasa inggris yang berarti pembalik. Sedangkan pengertian dari inverter adalah sebuah peralatan elektronik yang berfungsi untuk mengubah arus searah (DC) menjadi arus bolak-balik (AC) (Rashid, 2011, Charpentier et al, 2000).

Pada awalnya, inverter digunakan sebagai sumber listrik $A C$ yang dihasilkan dari batterai saat darurat ketika listrik PLN padam atau ditempat yang belum tersedia jaringan listrik PLN. Dalam kehidupan sehari-hari, inverter dapat dijumpai didalam perangkat elektronik seperti Pompa, kulkas, AC (Air Condition), UPS, dll.

Perangkat elektronik yang sudah berteknologi inverter tentu saja lebih unggul dibandingkan yang masih menggunakan sistem konvensional (tanpa inverter) (Doucet et al, 2007). Misalkan pada AC (air Condition) dan Kulkas berteknologi inverter digunakan untuk mengatur kerja kompresor sesuai dengan kebutuhan. Prinsip kerjanya adalah mengubah arus AC (bolak-balik) dari PLN menjadi DC (searah). Kemudian diubah lagi menjadi arus AC (bolak-balik) yang frekuensinya diatur secara otomatis oleh sensor suhu. Sehingga jika sudah dingin, sensor akan mengatur listriknya sehingga putaran kompresor menjadi lebih lambat, yang akan menghemat energi listrik (Malvino, 2003).

Selain mempunyai fungsi sebagai pengatur frekuensi, inverter juga berfungsi untuk mencegah arus asut (start) pada motor induksi, seperti pompa air. Jika motor dalam kondisi diam kemudian dihubungkan dengan sumber listrik biasanya akan menarik arus 5-8 kali dari arus nominal. Untuk motor daya kecil hal ini masih dapat diterima. Tetapi untuk motor dengan daya besar dan kapasitas supply listrik terbatas, cara untuk mengurangi arus asut ini menjadi sangat penting. Dengan menggunakan inverter yang mempunyai fitur kendali frekuensi dan tegangan, arus asut yang ditarik oleh motor hanya sekitar 1,5 kali arus nominal, namun juga tidak mengurangi nilai torsi awal. Sedangkan pada UPS (Uninterupptible power supply) inverter digunakan untuk mengubah tegangan searah dari baterai menjadi tegangan bolak-balik yang akan digunakan untuk supply listrik peralatan elektronik. UPS biasanya digunakan untuk komputer dan playstation. Fungsi UPS sendiri untuk menyediakan supply listrik sementara ke beban (komputer) tanpa terputus saat main powernya (listrik PLN) tidak bekerja. Agar seluruh proses dapat dihentikan dengan benar sehingga data dapat disimpan dengan aman.

Dalam dunia industri, inverter digunakan sebagai pengatur kecepatan putaran motor induksi. Kecepatan putar motor induksi dipengaruhi oleh 4 faktor, yaitu: jumlah kutub, frekuensi, tegangan, dan tahanan luar. Pengaturan kecepatan motor induksi dengan mengubah jumlah kutub dan mengatur tahanan luar tidak mungkin dilakukan, karena harus mengubah struktur/bentuk motor itu sendiri atau dengan kata lain harus membuat ulang motor induksii tersebut. Cara yang tepat yang digunakan untuk pengaturan kecepatan motor induksi adalah

TEKNO Vol. 28 Issue 1, p1-16 | Jurusan Teknik Elektro, Universitas Negeri Malang, Indonesia | Maret 2018

M. K. Wardana, I. Fadlika, A. Fahmi | Rancang Bangun Inverter Satu Fasa SPWM dengan Output Tegangan dan Frekuensi judul... 


\section{TEKNO Junal Teknologi, Eektro, dan Kejurvan}

http://journal2.um.ac.id/index.php/tekno | ISSN 1693-8739

mengubah frekeuensi dan tegangan terminal. Inverter yang digunakan dalam industri memiliki fitur tegangan dan frekuensi yang bisa diatur oleh pengguna.

Dalam paper ini, dirancang sebuah inverter satu fasa dengan output tegangan dan frekuensi variabel yang dapat digunakan untuk memenuhi kebutuhan beban rumah tangga. Eksperimen laboratorium dilakukan untuk memverifikasi desain yang telah dilakukan.

\section{Prinsip Kerja konverter SEPIC}

Gambar menunjukkan rangkaian sederhana dari konverter dc-dc SEPIC (Massey \& Snyder, 1977) yang terdiri dari sebuah kapasitor input (Cin), sebuah kapasitor output (Cout), sepasang induktor (Lia dan Lib), sebuah AC Coupling kapasitor (Cp), sebuah saklar elektronik (MOSFET), dan sebuah dioda.

Saat Q1 on , berlaku hubung singkat pada Q1 dan tegangannya adalah nol. Kapasitor coupling (Cp) diisi oleh Vin sehingga tegangan di VL1b menjadi sama dengan -Vin. Disisi lain dioda off dan positif sumber terputus dengan positif beban. Sehingga arus akan mengalir menuju negatif beban. Jika duty cycle diperbesar maka beban akan menjadi negatif.

Saat Q1 off, berlaku hubung buka pada Q1 dan tegangannya adalah Vin + Vout. Jadi tegangan di L1a adalah Vout. Disisi lain, dioda ON dan positif sumber terhubung dengan positif beban. Sehingga arus akan mengalir menuju positif beban. Jika Duty Cycle diperkecil, maka arus yang melalui positif beban menjadi lebih besar. Polaritas beban akan menjadi positif. Perbedaan tegangan saat $\mathrm{Q} 1$ off dan on dapat dilihat pada gambar.

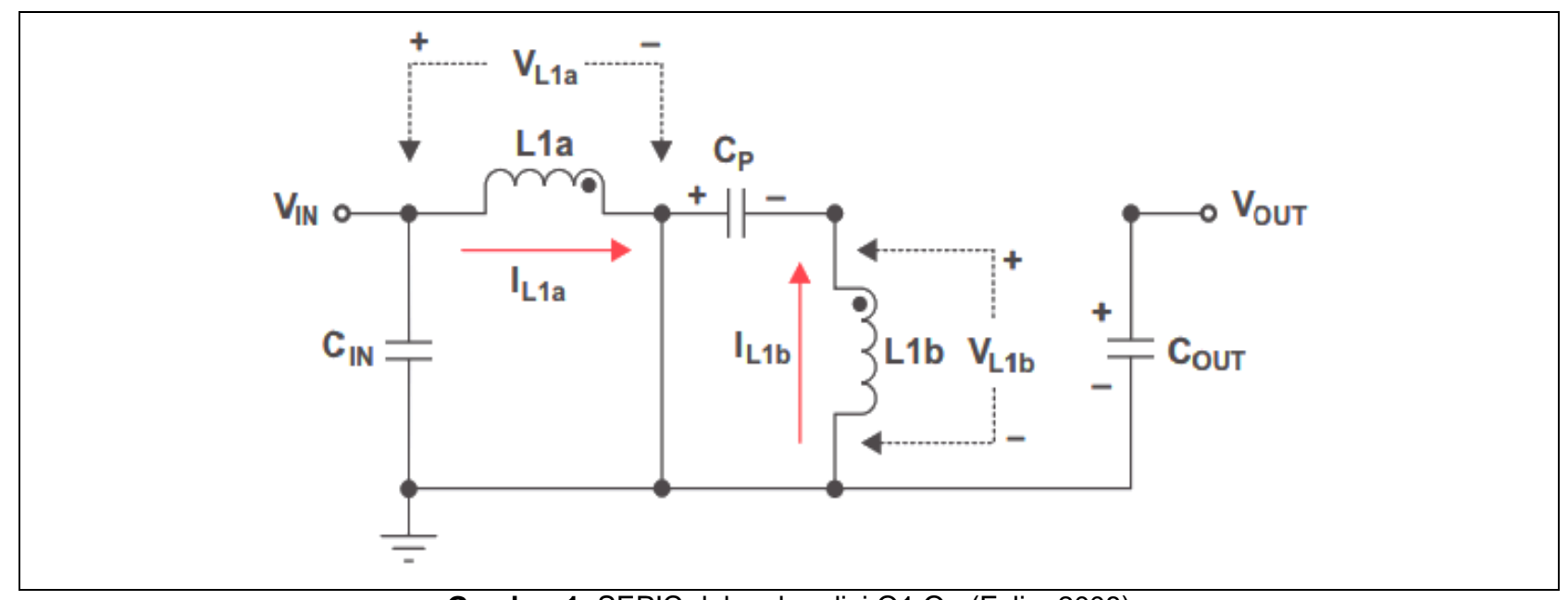

Gambar 1. SEPIC dalam kondisi Q1 On (Falin, 2008) 


\section{TEKNO Junal Teknologi, Ekekro, dan Kejuvran}

http://journal2.um.ac.id/index.php/tekno | ISSN 1693-8739

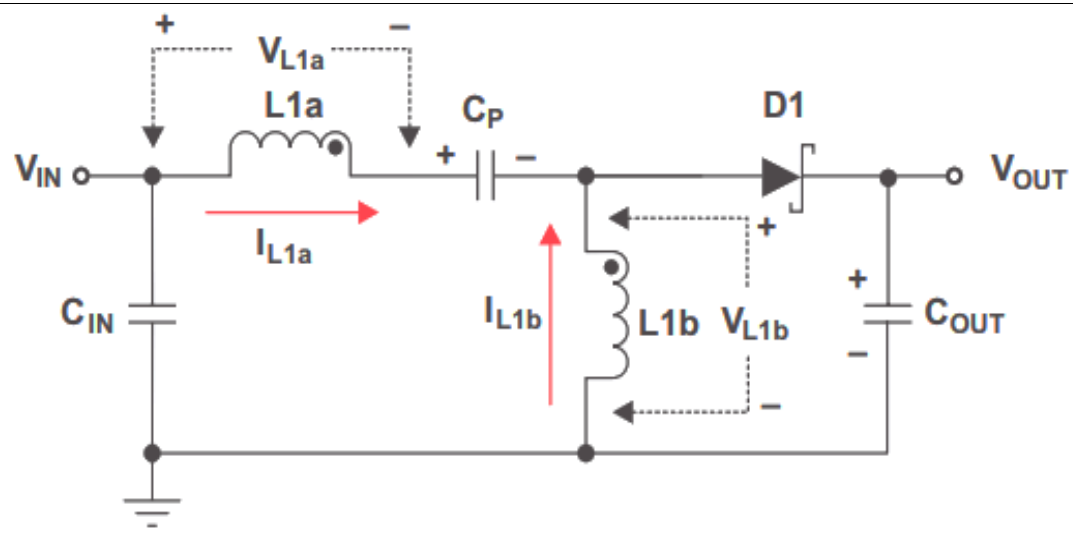

Gambar 2. SEPIC dalam kondisi Q1 Off (Falin, 2008)

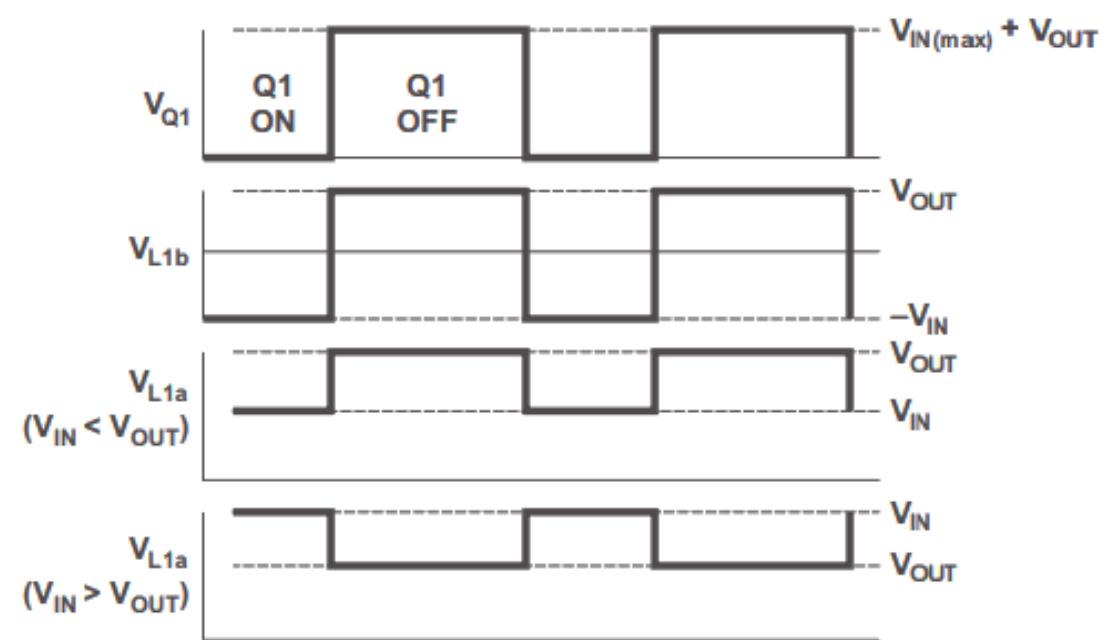

Gambar 3. Tegangan Pada Komponen-komponen SEPIC (Falin, 2008)

\section{Prinsip Kerja Inverter Satu Fasa}

Menurut jenis rangkaiannya inverter terbagi menjadi dua macam, yaitu half-bridge inverter dan full-bridge inverter. Gambar 4 menunjukkan rangkaian half-bridge inverter. Dimana dua kapasitor diperlukan untuk memberikan netral di titik $N$, sehingga setiap kapasitor mempertahankan nilai tegangan konstan vi/2. Kedua switch ( $\mathrm{S}_{+}$dan $\left.\mathrm{S}_{-}\right)$tidak boleh aktif bersamaan untuk menghindari hubung singkat. Detail penyaklaran inverter satu fasa half-bridge dijelaskan melalui Tabel 1. 


\section{TEKNO Jumal Teknologi, Eektro, dan kejivuan}

http://journal2.um.ac.id/index.php/tekno | ISSN 1693-8739

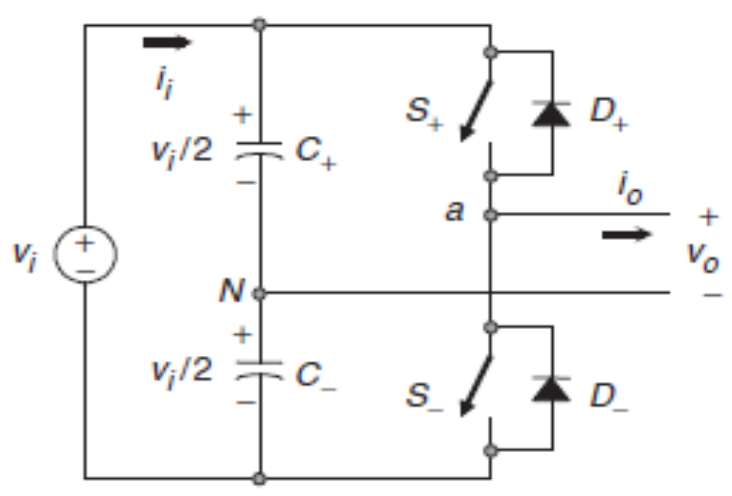

Gambar 4. Tegangan Pada Komponen-komponen SEPIC (Falin, 2008)

Tabel 1. Kondisi Switch half-bridge inverter

\begin{tabular}{lllll}
\hline No & Kondisi & Vo & Logika & \\
\hline 1 & S+ on dan S- off & vi/2 & S + & lo $>0$ \\
& & & D+ & lo $<0$ \\
2 & S+ off dan S- on & $-v i / 2$ & D- & lo $>0$ \\
& & & S- & lo $<0$ \\
3 & \multirow{3}{*}{ S+ dan S- off } & vi/2 & D- & lo $>0$ \\
& & & D+ & lo $<0$ \\
\hline
\end{tabular}

Gambar 5 menunjukkan rangkaian full-bridge inverter. Perbedaan dengan half-bridge inverter adalah inverter ini menggunakan 4 buah switch yang aktif berpasangan. Kedua switch S1 + dan S1- (atau S2 + dan S2-) tidak boleh aktif bersamaan. Untuk menghindari hubung singkat, maka logika pengaktifan saklar harus dibuat sedemikian rupa sesuai Tabel 2. Pada saat $\mathrm{S} 1+$ dan $\mathrm{S} 2-$ on, beban mendapatkan tegangan positif $(\mathrm{Vd})$. Dan saat $\mathrm{S} 1$ - dan $\mathrm{S} 2+$ on maka beban mendapatkan tegangan negatif $(-\mathrm{Vd})$. Detail penyaklaran pada inverter ini diberikan pada Tabel 2.

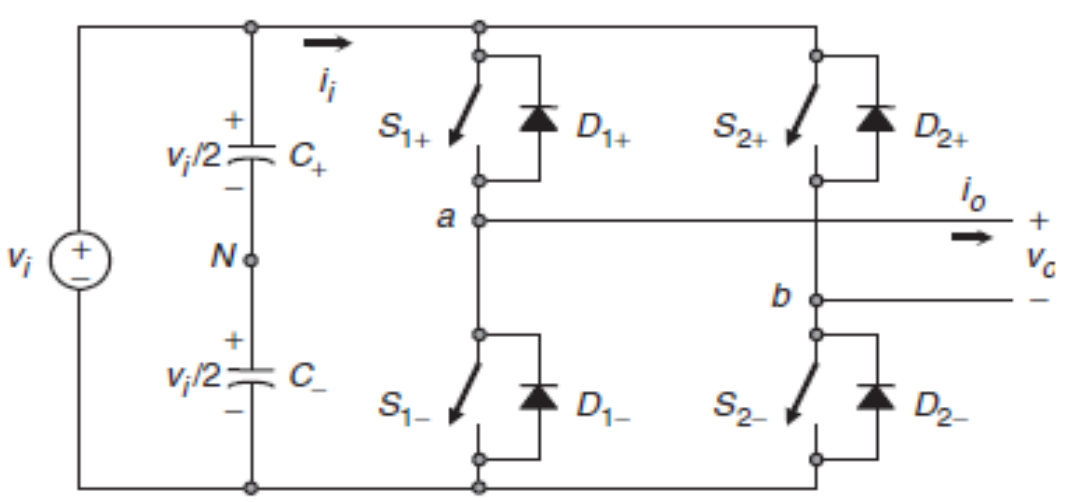

Gambar 5. Full-brridge inverter (Rashid, 2011)

TEKNO Vol. 28 Issue 1, p1-16 | Jurusan Teknik Elektro, Universitas Negeri Malang, Indonesia | Maret 2018

M. K. Wardana, I. Fadlika, A. Fahmi | Rancang Bangun Inverter Satu Fasa SPWM dengan Output Tegangan dan Frekuensi judul... 


\section{TEKNO Jumal Teknologi, Eektro, dan Kejurvan}

http://journal2.um.ac.id/index.php/tekno | ISSN 1693-8739

Tabel 2. Kondisi Switch Full-bridge inverter (Rashid: 2011)

\begin{tabular}{|c|c|c|c|c|c|c|}
\hline No & Kondisi & VaN & VbN & Vo & Logika & \\
\hline 1 & $\mathrm{~S} 1+$ dan S2- On, dan S1- dan S2+ off & $\mathrm{vi} / 2$ & $-v i / 2$ & Vi & $\begin{array}{l}\text { S1+ dan S2- } \\
\text { D1+ dan D2- }\end{array}$ & $\begin{array}{l}\text { lo }>0 \\
\text { lo }<0\end{array}$ \\
\hline 2 & S1+ dan S2- Off, dan S1- dan S2+ On & $-v i / 2$ & $\mathrm{vi} / 2$ & $-\mathrm{Vi}$ & $\begin{array}{l}\text { D1- dan D2+ } \\
\text { S1- dan S2+ }\end{array}$ & $\begin{array}{l}\text { lo }>0 \\
\text { lo }<0\end{array}$ \\
\hline 3 & $\mathrm{~S} 1+$ dan $\mathrm{S} 2+$ On, dan S1- dan S2- off & $\mathrm{vi} / 2$ & $\mathrm{vi} / 2$ & 0 & $\begin{array}{l}\mathrm{S} 1+\text { dan } \mathrm{D} 2+ \\
\mathrm{D} 1+\text { dan } \mathrm{S} 2+\end{array}$ & $\begin{array}{l}\text { lo }>0 \\
\text { lo }<0\end{array}$ \\
\hline 4 & S1+ dan S2+ Off, dan S1- dan S2- On & $-v i / 2$ & $-v i / 2$ & 0 & $\begin{array}{l}\text { D1- dan S2- } \\
\text { S1- dan D2- }\end{array}$ & $\begin{array}{l}\text { lo }>0 \\
\text { lo }<0\end{array}$ \\
\hline 5 & $\mathrm{~S} 1+, \mathrm{S} 2-, \mathrm{S} 1-, \mathrm{S} 2+$ semua off & $\mathrm{vi} / 2$ & $\begin{array}{l}v i / 2 \\
-v i / 2\end{array}$ & $\begin{array}{l}\mathrm{Vi} \\
-\mathrm{Vi}\end{array}$ & $\begin{array}{l}\text { D1- dan D2+ } \\
\text { D1 + dan D2- }\end{array}$ & $\begin{array}{l}\text { lo }>0 \\
\text { lo }<0\end{array}$ \\
\hline
\end{tabular}

\section{Sinusoidal Pulse Width Modulation (SPWM)}

SPWM adalah teknik modulasi yang paling umum digunakan untuk mengontrol komponen saklar semikonduktor pada inverter. Pada aplikasinya, teknik ini paling populer digunakan karena dipandang sederhana dan paling mudah. Penyaklaran pada tiap kaki inverter ini diperoleh dengan cara membandingkan gelombang referensi berupada gelombang sinusoidal dengan gelombang carrier berupa gelombang segitiga seperti yang terdapat pada gambar 6 (Gole, 2000). Logika pada tiap saklar semikonduktor dijabarkan sebagai berikut:

Jika $v_{r e f} \geq v_{T}$ maka $\mathrm{s}=1$

Jika $v_{\text {ref }}<v_{T}$ maka $\mathrm{s}=0$

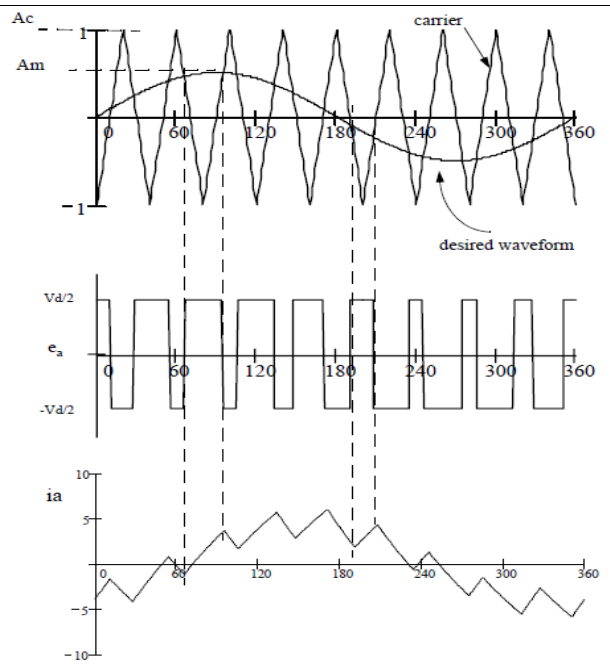

Gambar 6. Prinsip SPWM (Gole: 2000)

\section{Metode Perancangan Hardware}

TEKNO Vol. 28 Issue 1, p1-16 | Jurusan Teknik Elektro, Universitas Negeri Malang, Indonesia | Maret 2018

M. K. Wardana, I. Fadlika, A. Fahmi | Rancang Bangun Inverter Satu Fasa SPWM dengan Output Tegangan dan Frekuensi judul... 


\section{TEKNO Jumal Teknologi, Eektro, dan kejurvan}

http://journal2.um.ac.id/index.php/tekno | ISSN 1693-8739

Rancang bangun inverter satu fasa berbasis SPWM ini pada dasarnya dibagi menjadi dua bagian yaitu: Perancangan perangkat keras (hardware) dan Perancangan perangkat lunak (software / program). Perancangan perangkat keras meliputi 2 bagian besar, yaitu: (1) Rangkaian Daya, dan (2) Rangkaian Kendali. Rangkaian daya meliputi 3 sub rangkaian, yaitu: (a) Rangkaian Power Supply, (b) Rangkaian Buck Converter, dan (c) Rangkaian Inverter. Sedangkan untuk perancangan perangkat lunak dideskripsikan dalam bentuk flowchart, algoritma bahasa $\mathrm{C}$ dari flowchart uraian perangkat lunak:

1. Rangkaian Daya

Rangkaian Daya terdiri dari 3 sub rangkaian yaitu:

a) Rangkaian Power Supply.

Rangkaian power supply diperlukan sebagai sumber catu daya pada Inverter dan SEPIC Converter (mode buck/penurun tegangan). Rangkaian ini terdiri dari 3 macam, yaitu Power Supply 5V, Power Supply 12V, dan Power Supply Buck Converter. Power supply 5 $\mathrm{V}$ digunakan sebagai catu daya pada IC Driver MOSFET dapat bekerja (International Rectifier, 2005). Power Supply $12 \mathrm{~V}$ digunakan sebagai catu daya agar IC Driver MOSFET dapat memicu gate MOSFET. Sedangkan Power Supply Buck Converter digunakan sebagai catu daya pada rangkaian Buck Converter. Data lengkap penentuan komponen dapat dilihat pada Tabel 3.

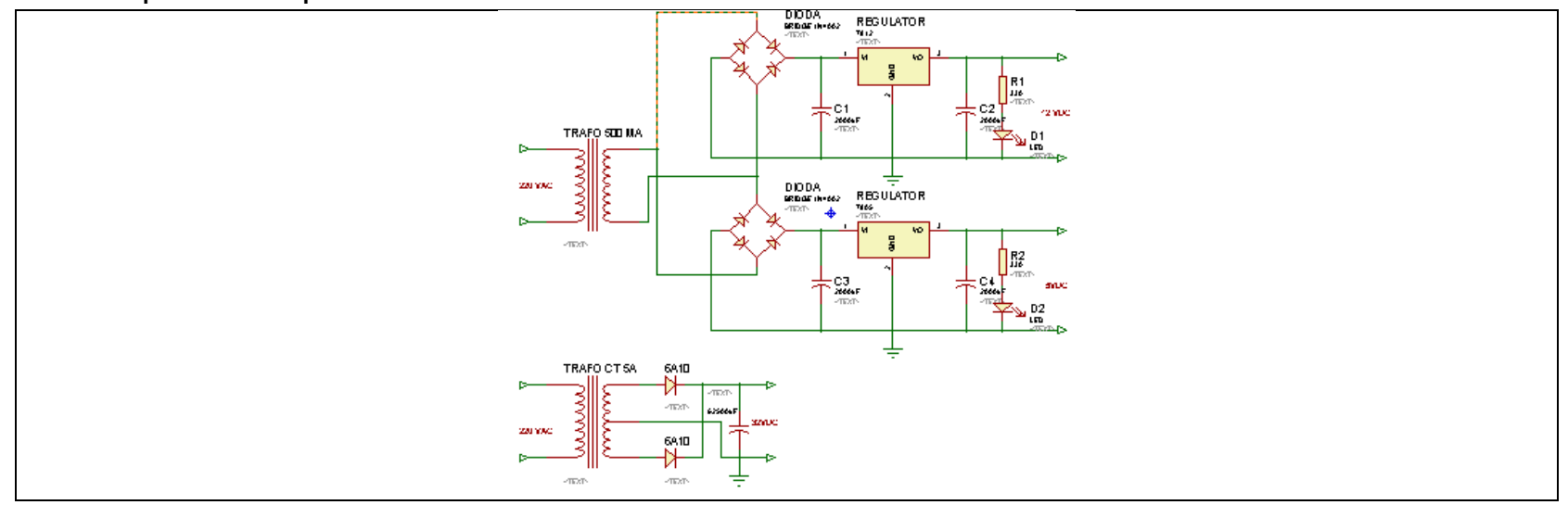

Gambar 6. Rangkaian power supply

b) Rangkaian Buck Converter.

DC-DC Converter, dengan spesifikasi sebagai berikut: (1) Tegangan Input: 4V - 35V, (2) Tegangan Output: 1,23V - 32V, dan (3) Arus Maksimum: 3A. 


\section{TEKNO Jurnal Teknologi, Elektro, dan Kejuruan}

http://journal2.um.ac.id/index.php/tekno | ISSN 1693-8739

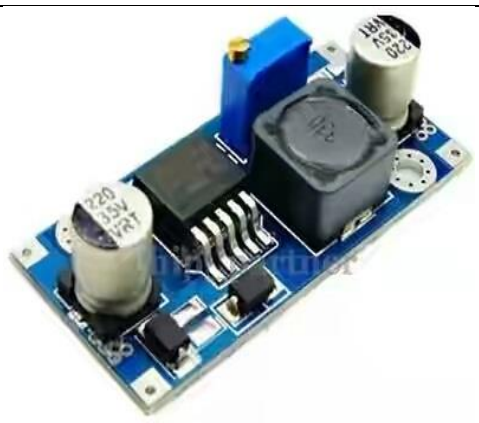

Gambar 8. Modul konverter dc-dc

Tabel 3 Data Rangkaian Power Supply

\begin{tabular}{llll}
\hline Power Supply & Power Supply 5V & Power Supply 12V & $\begin{array}{l}\text { Power Supply } \\
\text { Buck Converter }\end{array}$ \\
\hline Vin (Vac) & $5 \mathrm{~V}$ & $12 \mathrm{~V}$ & $25 \mathrm{~V}$ \\
Transformator & Netral 2A & Netral 2A & CT 5 A \\
Dioda & $1 \mathrm{N4002}$ & $1 \mathrm{~N} 4002$ & $6 \mathrm{~A} 10$ \\
Beban (Asumsi) & $2 \mathrm{~W}$ & $2 \mathrm{~W}$ & $200 \mathrm{~W}$ \\
Kapasitor & $3300 \mathrm{uF}$ & $3000 \mathrm{uF}$ & $62500 \mathrm{uF}$ \\
Regulator & 7805 & 7812 & - \\
Led & Ya & Ya & Tidak \\
Vout (Vdc) & $5 \mathrm{~V}$ & $12 \mathrm{~V}$ & $32 \mathrm{~V}$ \\
\hline
\end{tabular}

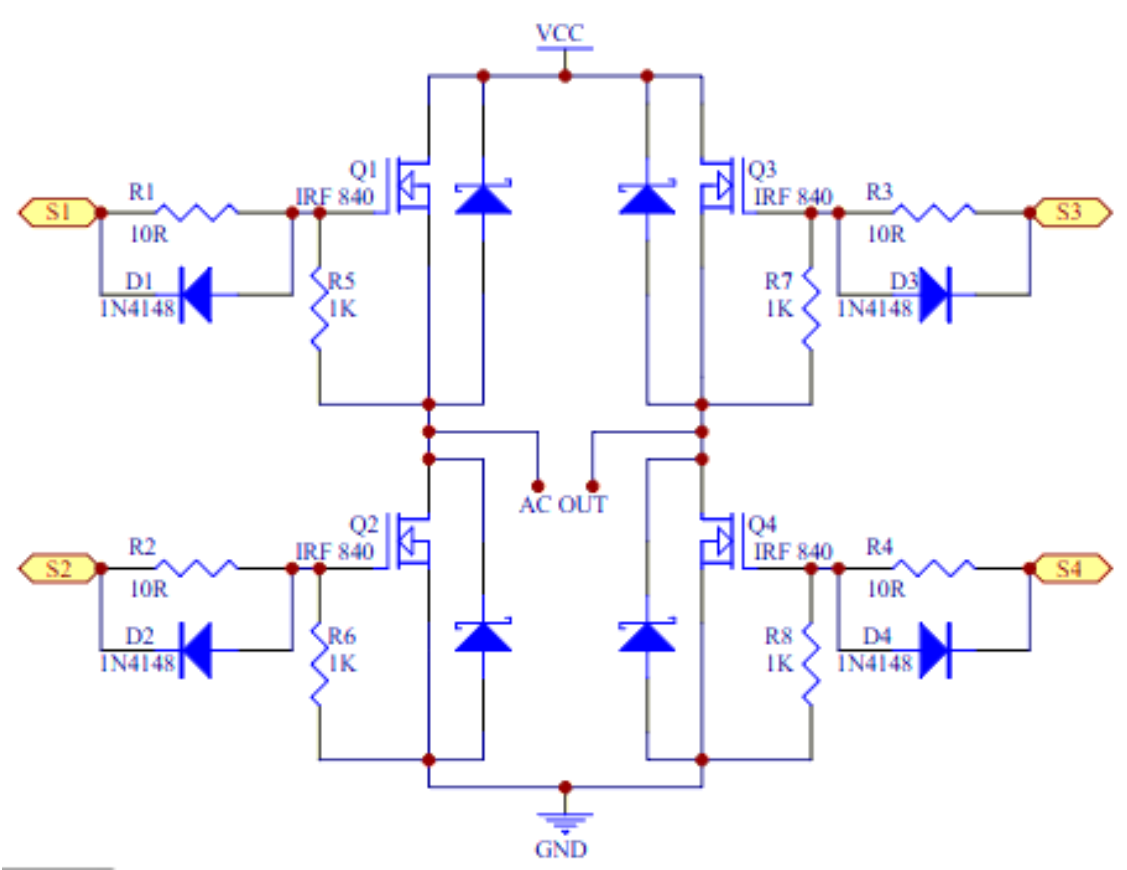

Gambar 9. Rangkaian Inverter Full-Bridge

TEKNO Vol. 28 Issue 1, p1-16 | Jurusan Teknik Elektro, Universitas Negeri Malang, Indonesia | Maret 2018

M. K. Wardana, I. Fadlika, A. Fahmi | Rancang Bangun Inverter Satu Fasa SPWM dengan Output Tegangan dan Frekuensi judul... 


\section{TEKNO Jumal Teknologi, Eektro, dan Kejuvran}

http://journal2.um.ac.id/index.php/tekno | ISSN 1693-8739

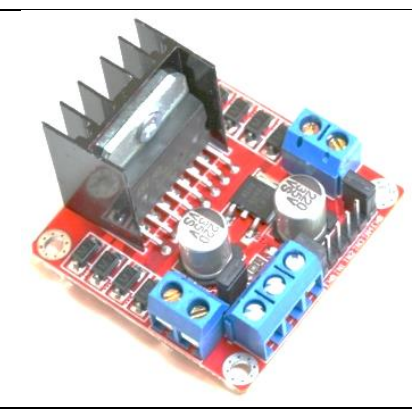

Gambar 10. Module LM298N Dual H-Bridge

c) Rangkaian Inverter

Rangkaian Inverter terdiri dari 2 bagian, yaitu: rangkaian Full Bridge Inverter, dan rangkaian driver MOSFET. Inverter yang digunakan pada paper ini adalah jenis Inverter full bridge. Inverter ini menggunakan 4 MOSFET sebagai saklar full bridge Inverter. MOSFET yang digunakan adalah tipe IRF840. Gambar rangkaian Inverter dapat dilihat pada Gambar 9. Karena MOSFET harus diberikan trigger sebesar \pm 12 Volt anatara Gate dan Source, sehingga rangkaian gate driver diperlukan untuk menaikkan tegangan dan memberikan isolasi galvanis antara inverter dan rangkaian kendalinya. Pada rancang bangun ini dipilih modul rangkaian gate driver LM298N Dual H-Bridge (Malvino, 2003) tampak pada Gambar 10.

2. Rangkaian Kendali

Rangkaian kendali, seperti diperlihatkan pada Gambar 11 digunakan untuk menghasilkan sinyal penyaklaran SPWM untuk masing-masing kaki MOSFET. Pada penelitian ini digunakan mikrokontroller (Atmel, 2010) yang sudah dilengkapi dengan rangkaian push button sebagai masukan. Rangkaian ini juga dilengkapi dengan downloader USB ASP agar memudahkan dalam mengisi program. 


\section{TEKNO Jurnal Teknologi, Elektro, dan Kejuruan}

http://journal2.um.ac.id/index.php/tekno | ISSN 1693-8739

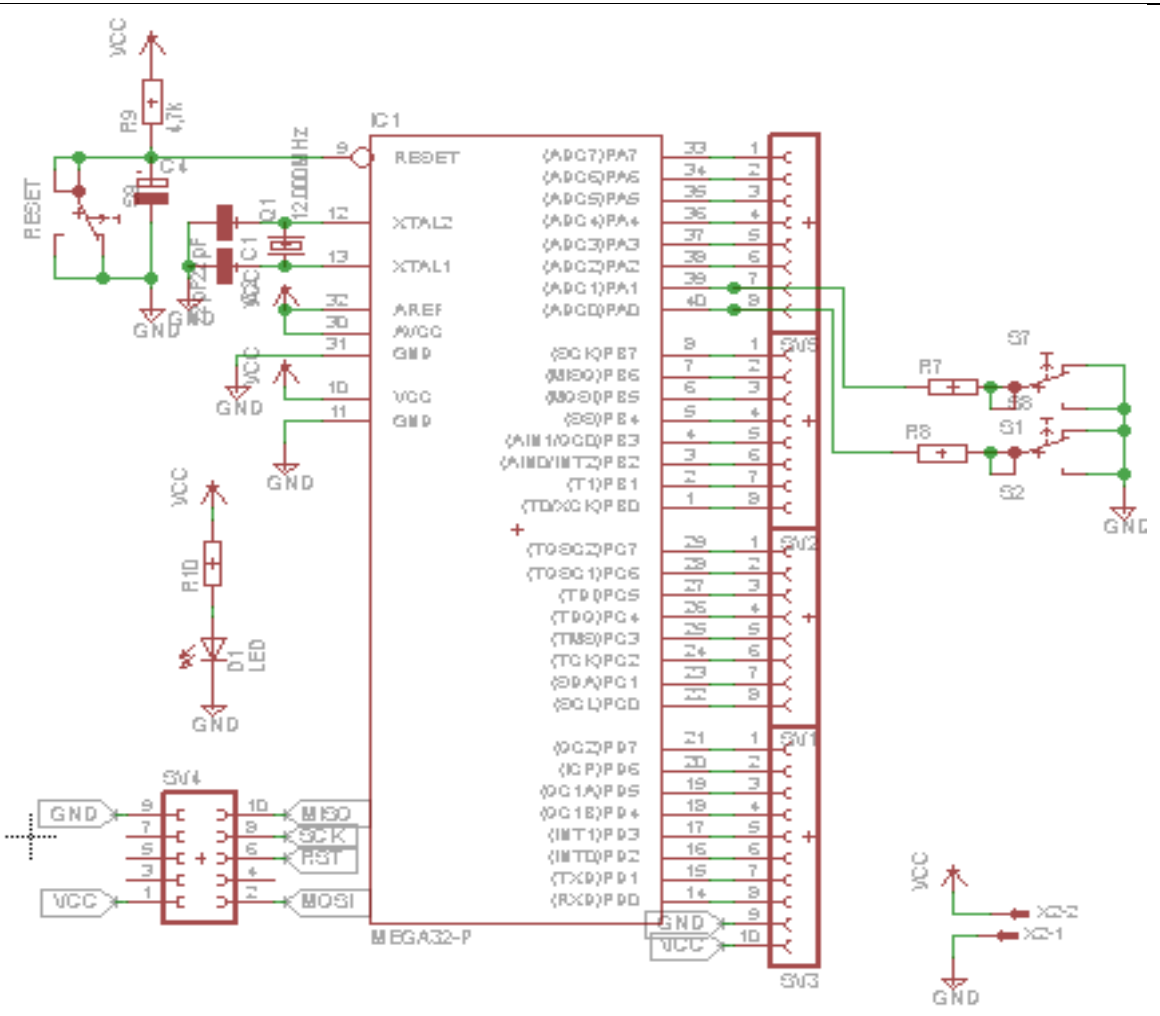

Gambar 11. Rangkaian Kendali

\section{Perancangan Algoritma SPWM}

Perangkat algoritma ini berisi perintah masukan data SPWM dari software PSIM untuk memicu keempat saklar MOSFET inverter. Gambar skema rangakaian pembentukan SPWM dapat dilihat pada gambar 12. SPWM diperoleh dengan membandingkan sinyal sinusoidal dengan sinyal segitiga. Sinyal modulasi yang digunakan sebanyak 2 buah, karena inverter ini menggunakan konfigurasi full bridge. Sinyal sinusoidal 1 dan 2 memiliki tegangan puncak yang sama yaitu sebesar $0.8 \mathrm{~V}$, beda sudut fasa sebesar 1800., dan frekuensinya disesuaikan dengan frekuensi yang diinginkan. Sedangkan parameter sinyal segitiga yang digunakan antara lain : Vpp sebesar 2 V, duty cycle 0,5 , dan frekuensi yang tetap yaitu $2500 \mathrm{~Hz}$. Setelah dibandingkan sinyal kemudian diolah lagi ke dalam rangkaian deadtime. Rangkaian deadtime berfungsi untuk menambahkan waktu jeda pada masing-masing lengan inverter (S1 dan S2; S3 dan S4) agar tidak terjadi perpindahan logika dari 0 ke 1 dan dari 1 ke 0 secara bersamaan. Rangkaian ini terdiri dari chip monostable dengan lebar pulsa sebesar 80 us dan gerbang NOT dan AND. Dari simulasi diatas, diperoleh bentuk sinyal SPWM seperti yang terlihat pada Gambar 13.

TEKNO Vol. 28 Issue 1, p1-16 | Jurusan Teknik Elektro, Universitas Negeri Malang, Indonesia | Maret 2018

M. K. Wardana, I. Fadlika, A. Fahmi | Rancang Bangun Inverter Satu Fasa SPWM dengan Output Tegangan dan Frekuensi judul... 


\section{TEKNO Junal Teknologi, Ekekro, dan Kejivuan}

http://journal2.um.ac.id/index.php/tekno | ISSN 1693-8739

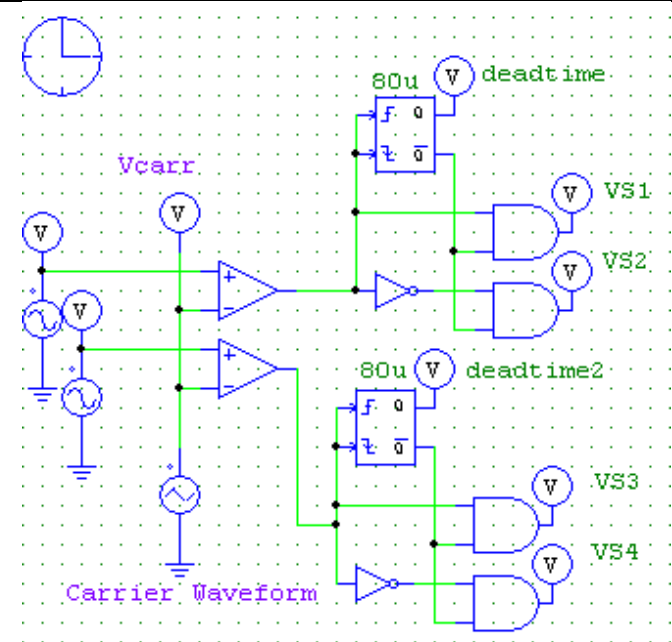

Gambar 12. Simulasi Pembentukan SPWM dengan mempertimbangkan deadtime

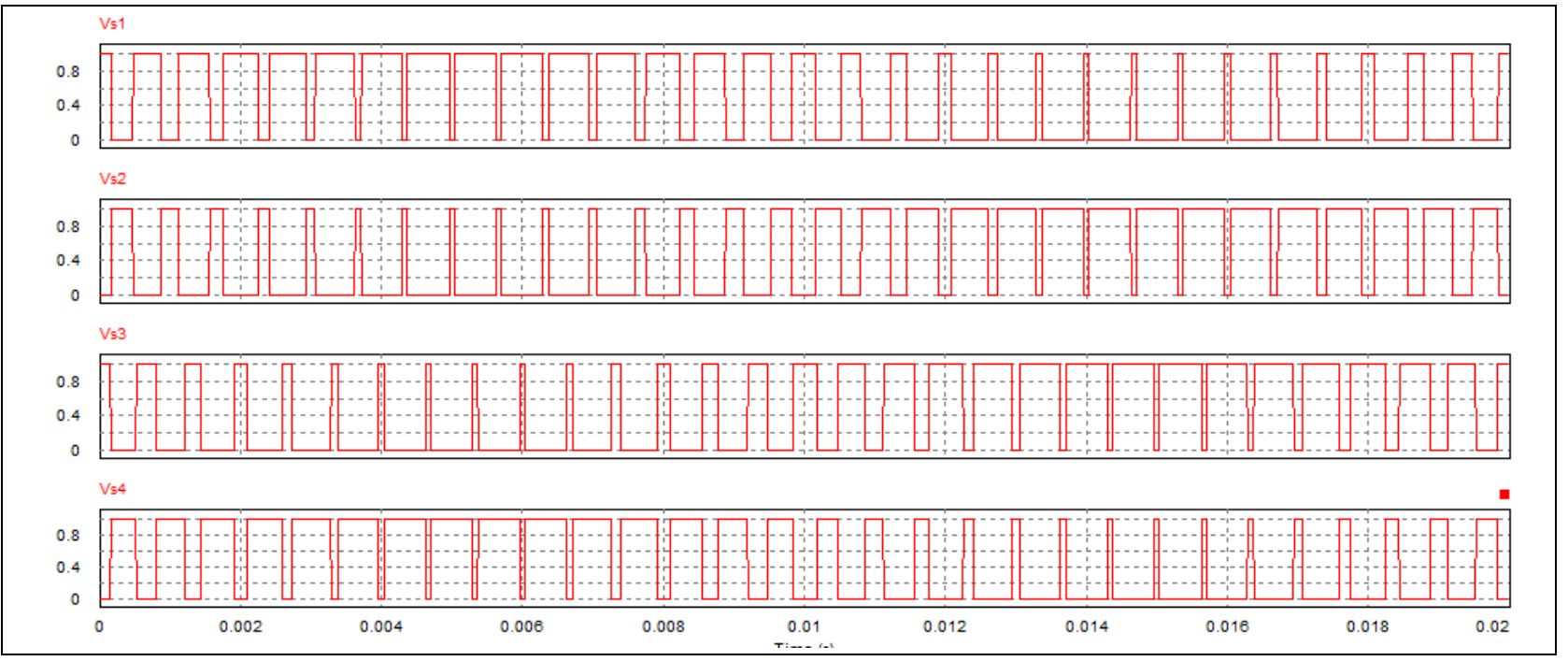

Gambar 13. Sinyal SPWM yang dihasilkan untuk masing-masing saklar MOSFET 


\section{TEKNO Jumal Teknologi, Eektro, dan kejurvan}

http://journal2.um.ac.id/index.php/tekno | ISSN 1693-8739

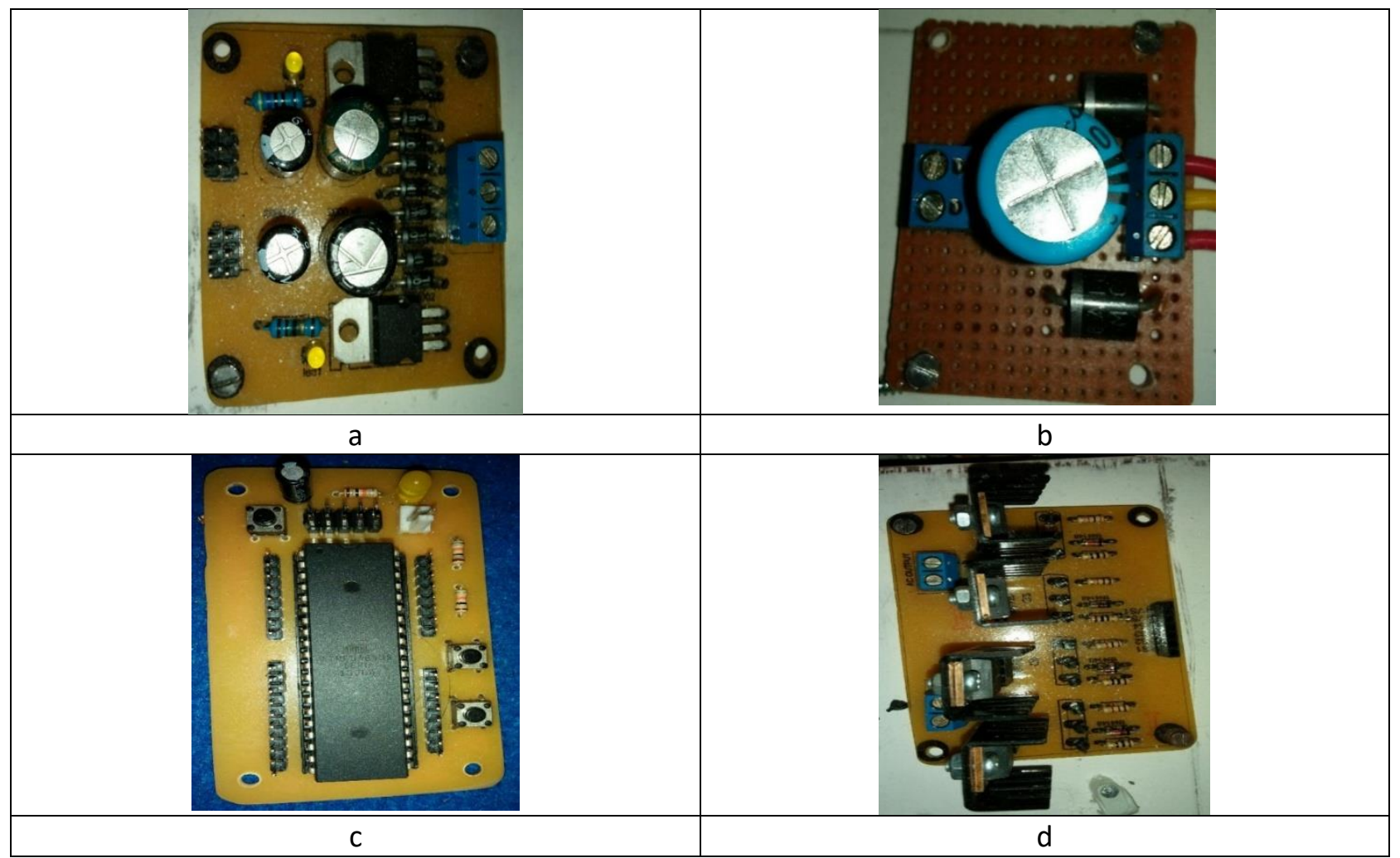

Gambar 14. a. Rangkaian Power Supply 5 V dan 12V, b. Rangkaian Power Supply dc-dc converter, c. Rangkaian Kendali, dan d. Rangkaian Inverter

\section{Hasil Eksperimen dan Analisis}

Dari perancangan yang telah dijelaskan sebelumnya, dilakukan rancang bangun prototipe, seperti pada Gambar 14. Eksperimen dilakukan di laboratorium dengan menggunakan alat ukur sesuai standar dan bertujuan untuk memvalidasi perancangan dan mengetahui kinerjanya.

1. Pengujian Rangkaian Kendali

Gambar 15 dan 16 menunjukkan output penyaklaran SPWM dari mikrokontroller. Dapat diketahui bahwa untuk sinyal SPWM dengan frekuensi $50 \mathrm{~Hz}$ panjang gelombangnya adalah 4 kotak x $5 \mathrm{~ms}=20 \mathrm{~ms}$. Dan untuk frekuensi $25 \mathrm{~Hz}$ panjang gelombangnya adalah 8 kotak x $5 \mathrm{~ms}$ = $40 \mathrm{~ms}$. Dari hasil tersebut diketahui bahwa sinyal SWPM yang dikeluarkan oleh Rangkaian kendali sudah berfungsi dengan baik. Gambar 17 menunjukkan output tegangan rangkaian gate driver yang digunakan untuk menyalakan MOSFET. Melalui gambar tersebut dapat dilihat bahwa baik frekuensi penyaklaran maupun tegangan penyaklaran rangkaian gate driver telah sesuai. 


\section{TEKNO Jurnal Teknologi, Elektro, dan Kejuruan}

http://journal2.um.ac.id/index.php/tekno | ISSN 1693-8739

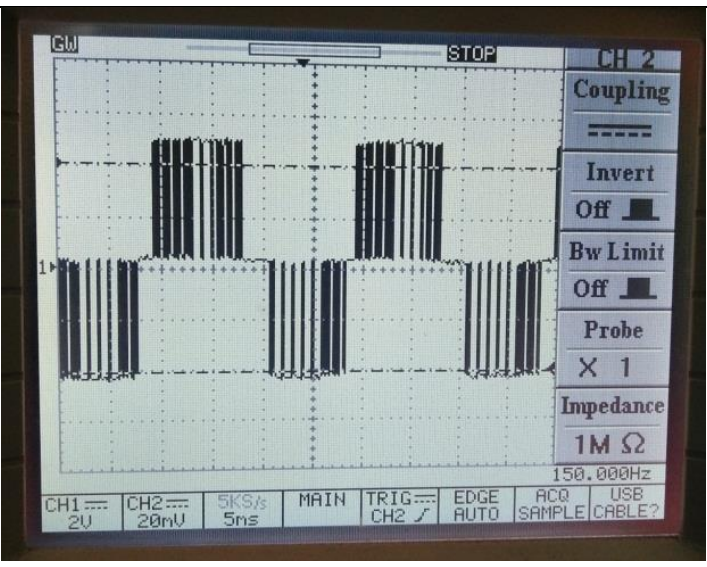

Gambar 15. Tegangan di PC0-PC2, dan PC1-PC3 frekuensi $50 \mathrm{~Hz}$ (2V/div, 5ms/div)

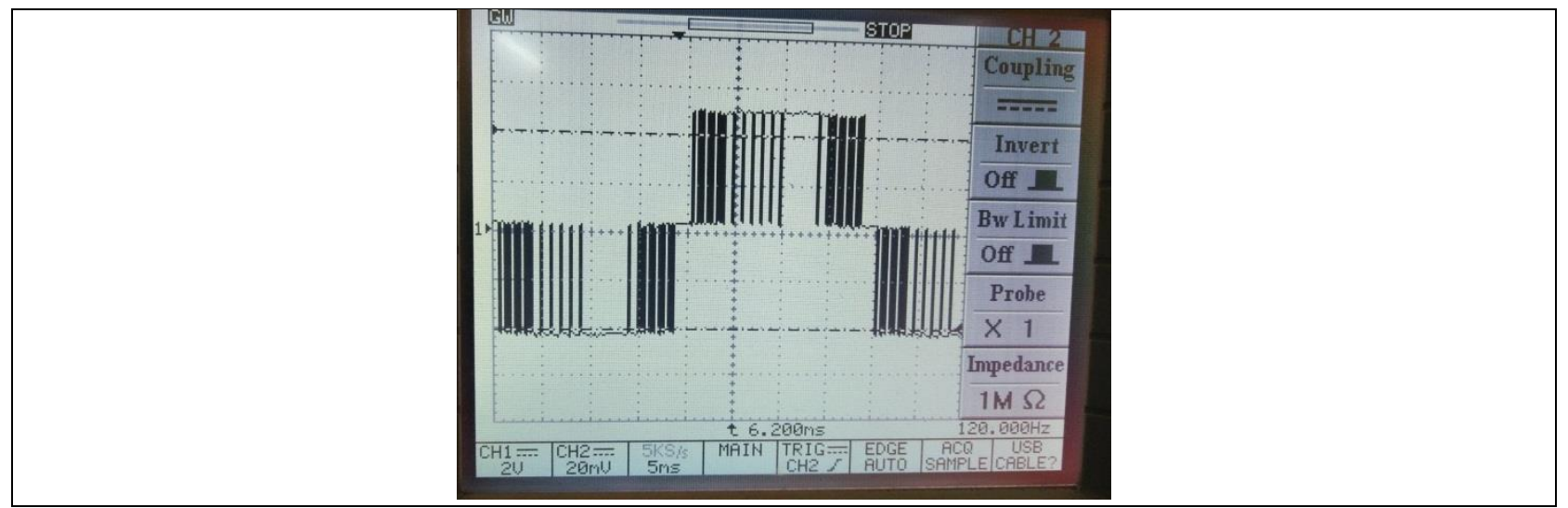

Gambar 16. Tegangan di PC0-PC2, dan PC1-PC3 frekuensi $25 \mathrm{~Hz}$ (2V/div, 5ms/div)

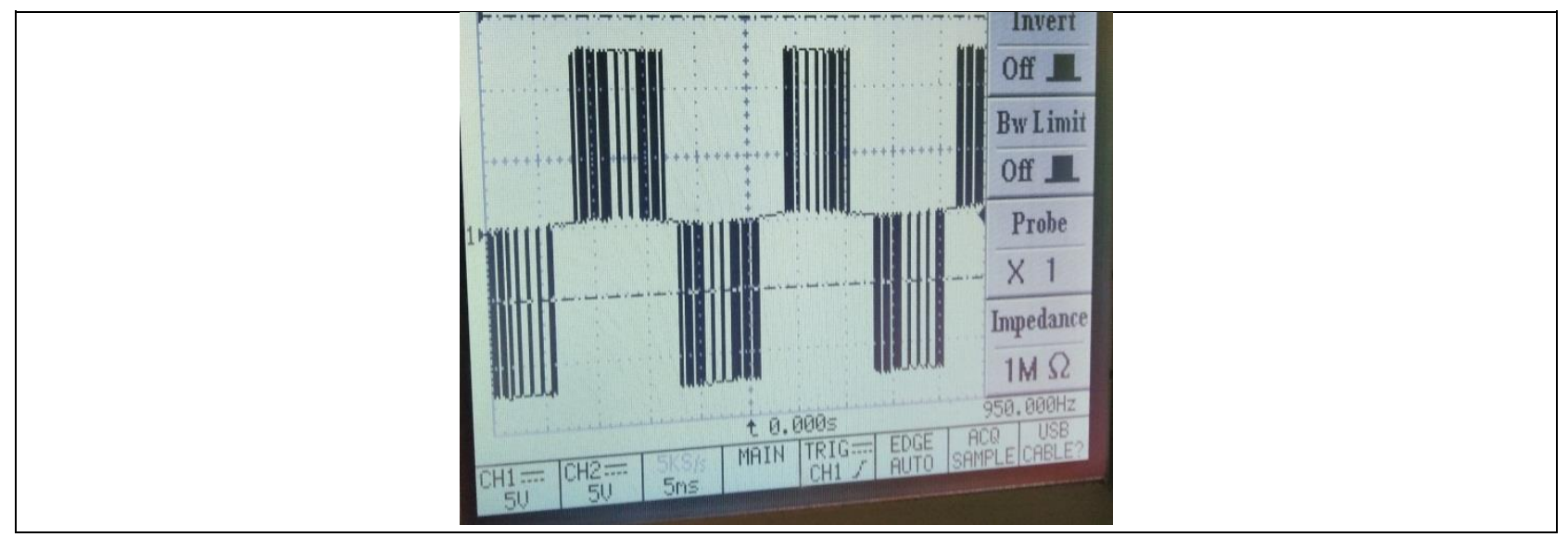

Gambar 17. Tegangan Keluaran Gate Driver (5V/div, 5ms/div)

TEKNO Vol. 28 Issue 1, p1-16 | Jurusan Teknik Elektro, Universitas Negeri Malang, Indonesia | Maret 2018

M. K. Wardana, I. Fadlika, A. Fahmi | Rancang Bangun Inverter Satu Fasa SPWM dengan Output Tegangan dan Frekuensi judul... 


\section{TEKNO Jumal Teknologi, Elekro, dan Kejuvuan}

http://journal2.um.ac.id/index.php/tekno | ISSN 1693-8739

\section{Pengujian Rangkaian Daya}

Pengujian rangkaian daya yang meliputi rangkaian inverter bertujuan untuk mengetahui apakah rangkaian ini mampu mengubah arus searah menjadi tegangan bolak-balik dengan baik atau tidak. Keluaran dari Inverter ini dihubungkan dengan transformator step up untuk menaikkan tegangan. Gambar 18 menunjukkan tegangan keluaran inverter setelah dihubungkan dengan transformator. Pemberian kapasitor digunakan untuk memfilter output tegangan, ditunjukkan oleh Gambar 18 a dan b. Gambar 19.a dan b masing-masing menunjukkan inverter yang terhubung dengan beban lampu, baik pada frekuensi 25 maupun 50 $\mathrm{Hz}$. Diketahui bahwa secara keseluruhan, inverter ini telah bekerja dengan baik.

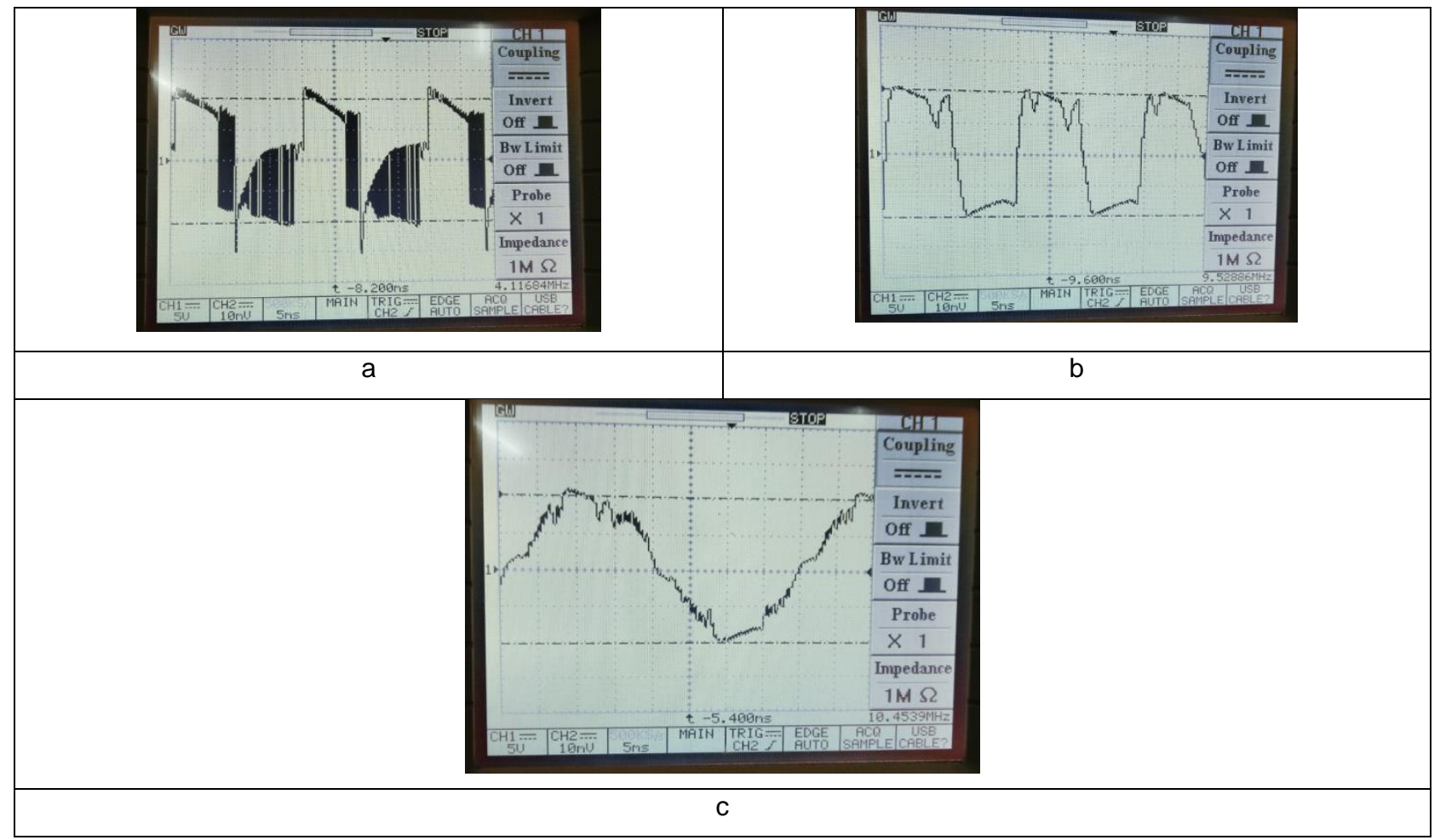

Gambar 18. a. Tegangan Beban tanpa filter kapasitor, b. Tegangan Beban Setelah Diberi Filter Kapasitor 1 uF (Frekuensi 50 Hz), Tegangan Beban Setelah Diberi Filter Kapasitor 1 uF (Frekuensi $25 \mathrm{~Hz}$ )

TEKNO Vol. 28 Issue 1, p1-16 | Jurusan Teknik Elektro, Universitas Negeri Malang, Indonesia | Maret 2018

M. K. Wardana, I. Fadlika, A. Fahmi | Rancang Bangun Inverter Satu Fasa SPWM dengan Output Tegangan dan Frekuensi judul... 


\section{TEKNO Junal Teknologi, Eektro, dan kejuvuan}

http://journal2.um.ac.id/index.php/tekno | ISSN 1693-8739

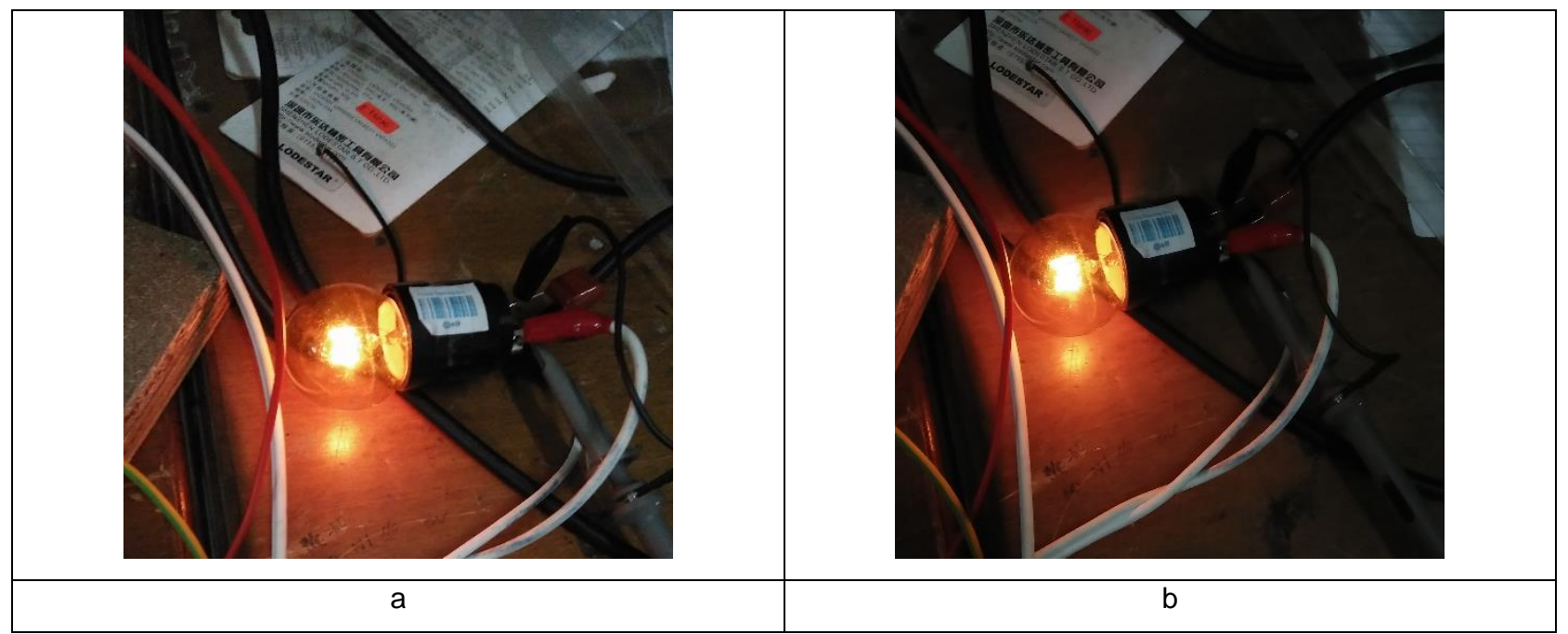

Gambar 19. a. Nyala Lampu Pada Frekuensi $50 \mathrm{~Hz}$, b. Nyala Lampu pada frekuensi $25 \mathrm{~Hz}$

\section{Kesimpulan}

Berdasarkan hasil pengujian prototipe di laboratorium dan analisis yang telah dilakukan, dalam penelitian ini, dapat disimpulkan bahwa dalam rancang bangun Inverter satu fasa SPWM telah bekerja sesuai dengan perencanaan, dengan rincian sebagai berikut:

1. Tegangan Keluaran yang dihasilkan bervariasi dalam skala 25-100 Volt.

2. Frekuensi keluaran inverter dapat dipilih sesuai keinginan, antara $25 \mathrm{~Hz}$ dan $50 \mathrm{~Hz}$

3. Inverter ini teruji dapat digunakan untuk menyuplai beban rumah tangga.

\section{Ucapan Terima Kasih}

Penulis mengucapkan terimakasih Fakultas Teknik Universitas Negeri Malang yang memfasilitasi penelitian ini melalui skema hibah penelitian PNBP tahun anggaran 2016.

\section{References}

Atmel. 2010. 8-bit AVR Microcontroller with 16K Bytes In-System Programmable Flash :

ATMega 16 ATMega 16L. Datasheet, Rev. 2466T-AVR-07/1

Charpentier, J.P.; Ruderval 1, Roberto Sharma, Raghuveer. 2000. High Voltage Direct Current

Transmission Systems. Technical Review Paper, 2000:1.

Doucet, Jim., Eggleston, Dan., Shaw, Jeremy. 2007. DC/AC Pure Wave Inverter. Worcester:

Worcester Polytechnic Institute

Falin, Jeff. 2008. Power Management: Designing DC/DC Converters Based on SEPIC

Topology. Texas: Texas Instruments Incorporated

Gole, A. M. 2000. Power Electronic: Sinusoidal Pulse Width Modulation. 


\section{TEKNO Jurnal Teknologi, Elektro, dan Kejuruan}

http://journal2.um.ac.id/index.php/tekno | ISSN 1693-8739

International Rectifier. 2005. IR2110(-1-2) (S)PbF/IR2113(-1-2) (S)PbF High and Low Side Driver. Datasheet, PD60147 rev. U

Malvino, Albert Paul.2003. Prinsip-Prinsip Elektronika. Edisi ke 1. Diterjemahkan oleh: Santoso, Joko. Jakarta: Salemba Teknika

Massey, R. P., \& Snyder, E. C. (1977, June). High voltage single-ended DC-DC converter. In 1977 IEEE Power Electronics Specialists Conference (pp. 156-159). IEEE.

Rashid, Muhammad H. 2011. Power Electronics Handbook: Devices, circuits, and Applications (Third Edition). Florida: Elsevier. 